\title{
AS POSSIBILIDADES DO OLHAR ESTÉTICO DO AFETO: O PROJETO OLHAR COMPLEXO
}

\author{
THE POSSIBILITIES OF THE AESTHETIC LOOK OF AFFECT: \\ THE COMPLEX LOOK PROJECT
}

\begin{abstract}
Lia Beatriz Teixeira Torraca
Doutorado em Direito, Programa de Pós-Graduação em Direito da Universidade Federal do Rio de Janeiro - PPGD/UFRJ. Rio de Janeiro, Rio de Janeiro - Brasil

liatorraca@icloud.com
\end{abstract}

\begin{abstract}
Resumo: Este artigo apresenta o Projeto Olhar Complexo, criado e dirigido pelo Fotógrafo Bruno Itan, como possibilidade do olhar estético do afeto, uma técnica desenvolvida durante o curso de doutorado em Direito pela Universidade Federal do Rio de Janeiro (PPGD/UFRJ), que buscou oferecer uma alternativa para o enfrentamento da violência no Rio de Janeiro a partir da hipótese que esta violência reflete uma dinâmica circular de comunicação, sendo possível alterá-la através da experiência perceptiva. É a possibilidade de transformar o padrão comunicativo em uma cidade cuja projeção de imagens rotuladas instauram um fluxo permanente de manifestações de violência entre dois territórios, entre morro e asfalto. Uma técnica que pretende não só fazer visível as formas dessa violência, mas alterar a percepção sobre aquilo que é comunicado como violência, tendo como referência metodológica a Fenomenologia da Percepção, de Maurice Merleau-Ponty. A experiência fotográfica pode ser o medium desta técnica que "faz ver" e "faz agir sobre", permitindo a reterritorialização da cidade e suas relações.
\end{abstract}

Palavras-chave: Comunicação. Educação. Estética. Fotografia. Violência.

\begin{abstract}
This article presents the Complex Look project, created and directed by Photographer Bruno Itan, as a possibility of the aesthetic look of affect, a technique developed during the doctoral course in Law at the Federal University of Rio de Janeiro (PPGD/UFRJ), which sought to offer an alternative to face violence in Rio de Janeiro, based on the hypothesis that this violence reflects a circular dynamic of communication, being possible to change it through the perceptual experience. It is the possibility of transforming the communicative pattern in a city whose projection of labeled images establishes a permanent flow of manifestations of violence between two territories, between slum and asphalt. A technique that aims not only to make visible the forms of this violence, but to change the perception of what is communicated as violence, having as methodological reference the Phenomenology of Perception, by Maurice Merleau-Ponty. The photographic experience can be the medium of this technique that "makes you see" and "makes you act on", allowing the reterritorialization of the city and its relations.
\end{abstract}

Keywords: Communication. Education. Aesthetics. Photography. Violence.

\section{Para citar - (ABNT NBR 6023:2018)}

TORRACA, Lia Beatriz Teixeira. As possibilidades do olhar estético do afeto: o projeto olhar complexo. Eccos - Revista Cientifica, São Paulo, n. 53, p. 1-17, e16666, abr./jun. 2020. Disponível em: https://doi.org/10.5585/eccos.n53.16666. 


\section{Introdução}

Entender a violência por intermédio da estética é perceber como a violência ganha formas, como é comunicada e significada. Uma comunicação que modula as relações em uma cidade conhecida mundialmente como maravilhosa, estruturada ao redor da violência e dividida entre espaços de inclusão e outros marginalizados, entre as desigualdades que separam os dois territórios. Uma segregação que reflete a própria circularidade de violência, tal como Paul Watzlawick descreve o padrão de interdependência comunicativa (WATZLAWICK, 1991, p. 93), entre o racismo escamoteado, a aporofobia despercebida, e outras formas de violência que acabaram normalizadas. Esta dinâmica comunicativa se reflete no comportamento do sujeito, o qual determina e é determinado pelo comportamento do outro, conforme observado por Watzlawick (Ibid., p. 93). A ordem é, então, fixada sob uma dinâmica comunicativa de ameaça constante e recíproca, uma percepção disseminada pela mídia e pelo estado através do discurso da guerra e do terror, e assimilada pela sociedade, que passa a exigir mais proteção e segurança, legitimando medidas de contenção e controle que retroalimentam a circularidade da violência e potencializam esta violência em ambos os espaços. Até mesmo a paz se apresenta como face da violência da cidade, ao atrelar a percepção de segurança à imagem de uma polícia que carrega símbolos violentos, como o emblema do Batalhão de Operações Especiais da Polícia Militar do Estado do Rio de Janeiro, uma caveira atravessada por um punhal, popularmente chamada de "faca na caveira", significada como "morte aos bandidos". Esta imagem da polícia acaba por substituir a imagem da justiça por uma ideia de justiçamento.

A realidade social carioca expõe como o problema da violência se afasta de uma solução possível por insistirem em formular unilateralmente esta solução, restrita à contenção seletiva daqueles que são considerados criminosos em razão de uma imagem fabricada, gerando ainda mais exclusão e marginalização, consequentemente, mais violência. Ao deslocar o enfoque, buscando novas perspectivas de analisar e enfrentar a violência, é possível articular a questão de outra maneira ao considerar esta violência como uma circularidade que se retroalimenta e se autorregenera. A circularidade da violência, portanto, é a forma como se estabelece a percepção e a construção da realidade, ou seja, como a cidade se comunica. É a forma como vemos o outro, como o outro nos olha, pontua Didi-Huberman. A partir do olhar do outro é possível estabelecer outra forma de comunicação e construir uma imagem que não reproduza a comunicação violenta. A Fotografia carrega a potência desta experiência perceptiva transformadora, que converte o ver em olhar a partir de outra perspectiva, capaz de afetar e fazer agir através do afeto. 
Para construir o olhar estético do afeto, a "Fenomenologia da Percepção", de Maurice Merleau-Ponty, foi não só o principal referencial teórico sobre estética, mas a metodologia desta pesquisa. A fenomenologia merleaupontyana é um método para descrevermos nossa percepção sobre o mundo a partir do nosso mundo interior, pretendendo uma descrição direta da nossa experiência - vivida e diária, daquilo que nos afeta, das sensações, das imagens mentais e das lembranças, localizando o observador do sujeito perceptivo como um sujeito perceptivo. Este método é um convite aquilo que é essencial na percepção: abrir-se a um outro e sair de si (MERLEAU-PONTY,1999, p. 571), dispondo o corpo no centro desta relação com o mundo; afinal, "meu corpo é a potência do espetáculo" (Ibid., p. 406) e "a percepção é a iniciação ao mundo" (Ibid., p. 346). O mundo percebido é aquele revelado a partir da experiência do sujeito, do seu olhar sobre o mundo através do seu "mundo humano", do seu intermundo, explicam Lopes e Pimentel (LOPES; PIMENTEL apud ROCHA, 2011, p. 101-103). Por intermédio de uma fenomenologia da percepção é possível observar como se constrói a realidade e descrever a experiência perceptiva. $\mathrm{O}$ mundo fenomenológico merleaupontyano nos permite ir além da empatia, ele desperta nossa simpatia pelo outro, conforme orienta Adela Cortina (CORTINA, 2017). Essa simpatia significa o nosso comprometimento com a vida desse outro. Rocha e Medeiros defendem que a fenomenologia como método é uma "alternativa à dialética já conhecida e que não se orienta necessariamente para o exame de um problema, mas para a contemplação do objeto investigado" (ROCHA; MEDEIROS apud ROCHA, 2011, p. 39), além de promover o desvelar do invisível no objeto examinado. Por ser uma opção inserta no campo da significação intersubjetiva, a abordagem fenomenológica autoriza e propicia a contínua análise e reflexão nos mundos dos quais se origina, constituindo-se em um método de apreensão da realidade, de acordo com Rocha e Medeiros (Ibid., p. 23; 40). Para dar conta da atualidade, não se pode buscar reduzir a complexidade das relações sociais, nem pensar na estabilização do ambiente, advertem Niklas Luhmann e Raffaele De Giorgi (LUHMANN; DE GIORGI, 2003); faz-se necessário experimentar a potência da percepção, pois é esta que tem sido alvo de calibragem e disputas por seu controle e alteração. O pensamento fenomenológico, centralizado no campo da filosofia, torna possível a libertação do ver e da experiência perceptiva.

A fenomenologia merleaupontyana é um método de abordagem que nos dá o ser presente e vivo, aplicável à relação do homem, seja com o próprio homem ou com os mais diversos campos da vida e do sensível (MERLEAU-PONTY, 2015, p. 50). Merleau-Ponty foca na experiência perceptiva e não no objeto da percepção, o que justifica a importância dada à perspectiva, decisiva para a percepção e não para o objeto percebido. Afinal, o objeto não possui apenas o lado que vejo, há a face não vista, “o lado oculto está presente à sua maneira. Ele está 
na minha vizinhança" (Ibid., p. 34). É no entorno do percebido que reside a possibilidade de "ver melhor o próprio percebido" (Ibid., p. 35), daquilo que é afetado por outras dimensões. A percepção é, portanto, um paradoxo, e a própria coisa percebida é paradoxal (Ibid., p. 37), "ela não existe senão enquanto alguém puder percebê-la" (Ibid., p. 37); logo, o visto não pode ser reduzido apenas à minha experiência. A fenomenologia de Merleau-Ponty vai além do método, capaz de produzir autorrevoluções, porquanto vivemos o primado da percepção, do paradoxo da imanência e da transcendência, do mundo complexo entre visível e invisível. O primado da percepção é o convite para experimentar um mundo não dicotômico e maniqueísta, aquele desenhado a partir do olhar do outro, afinal, "estamos todos em uma experiência do eu e de outrem que procuramos dominar pensando-a, mas sem jamais podermos nos vangloriar de fazêlo completamente" (Ibid., p. 58-59). Para Merleau-Ponty, o primado da percepção seria o remédio para o ceticismo e para o pessimismo (Ibid., p. 51-52), a possibilidade da comunicação através de uma sensibilidade aberta (Ibid., p. 52).

Considerada a fenomenologia merleaupontyana como método de pesquisa que localiza a experiência no centro da investigação, a sensação se configuraria como importante substrato de observação, pois, segundo o filósofo, ela pode "nos ensinar a relação viva daquele que percebe com seu corpo e com seu mundo" (MERLEAU-PONTY, 1999, p. 281), levando-se em conta que a sensação "não é nem um estado, nem uma qualidade, nem a consciência de um estado ou de uma qualidade" (Ibid., p. 281), mas qualidades sensíveis (Ibid., p. 281). Apoiada nesta perspectiva, buscou-se nesta pesquisa o duplo aspecto da fenomenologia, a atitude reflexiva da evidenciação e do consequente reflexo desta experiência no mundo ao seu redor, conforme orientam Lopes e Pimentel (LOPES; PIMENTEL apud ROCHA, 2011; p. 29; 37). Os autores propõem uma metodologia de pesquisa voltada para a fenomenologia merleaupontyana, não só por buscar o significado da experiência, mas por configurar-se em um método crítico por excelência e precioso instrumento cognitivo (LOPES; PIMENTEL apud ROCHA, 2011; p. 93). Um método apontado pelos autores como adequado à pesquisa em razão do seu caráter descritivo, especialmente no tocante às percepções sobre as significações. Neste sentido, há que se ressaltar tratar-se de uma investigação empírica, teórica, descritiva e propositiva, com o objetivo de refletir sobre as ideologias que sustentam e alimentam a circularidade, sobre as formas como a cidade torna visível a engrenagem e a (re)produção da violência, e sobre a possibilidade de rompimento da dinâmica circular de violência que marca a cidade e suas relações. Entende-se como pesquisa empírica a intenção de codificar a face mensurável da realidade social, como também, interpretar a objetividade da realidade cultural, não perdendo de vista o objetivo desta proposta, qual seja, realizar "ações transformadoras 
durante o percurso da investigação ou avaliações que se realizem para a constituição de novos rumos para a realidade social" (GUSTIN, 2010, p. 40). Essa perspectiva foi essencial para a construção do olhar estético do afeto; afinal, consoante José de Souza Martins, "a interferência interpretativa do pesquisador se dá no desvendamento das conexões entre o visível e o invisível, entre o que chega à consciência e o que se oculta na alienação da própria vida social" (MARTINS, 2017, p. 14). Diante desta perspectiva, o papel do pesquisador vai além da produção de conhecimento, defende Martins: "ao entrar na realidade investigada interage e, ao interagir, altera necessariamente o conhecimento do senso comum referencial das populações estudadas" (Ibid., p. 14); sem desprezar o fato da informação obtida restar contaminada pela presença do pesquisador, enfatiza o autor. Optar pela fenomenologia merleaupontyana implica, por conseguinte, não só a possibilidade de compreensão do amplo contex to no qual o objeto de pesquisa está inserto (ROCHA, 2011, p. 107), mas contemplar todos os aspectos levantados nesta introdução.

\section{$2 \mathrm{O}$ olhar estético do afeto}

A imagem da violência no Rio de Janeiro é uma imagem construída para ser percebida por intermédio de determinada lente, aquela imposta pelo asfalto, que enxerga o morro de forma violenta. Ao trocar essas lentes é possível alterar o olhar e construir outra imagem a partir de outra percepção sobre o outro, sobre o outro espaço. Um olhar que não enxergará mais uma ameaça no outro - diferente. Desta maneira, o outro também deixará de olhar-me como ameaça, rompendo a dinâmica circular de violência. A Fotografia faz possível alterar este olhar e construir outra imagem, estabelecer outro padrão comunicativo. $O$ afeto é a lente que transforma este olhar. O olhar estético do afeto oferece a possibilidade da construção de um novo olhar a partir da experiência estética (BERLEANT, 2000), considerada por Arnold Berleant como a mais completa experiência perceptiva (Ibid., p.121-122), capaz de incluir a experiência afetiva. Vale lembrar que estética se refere aquele que nota, percebe, afeta e é afetado. A estética é a teoria do conhecimento sensível (estesiologia), do despertar; "é uma forma de qualificar uma propriedade emocional intrínseca de toda função visual" (CATALÀ DOMÈNECH, 2011, p. 28), comprovando que nos afetamos em diversas possibilidades de graduação, o que leva Català Domènech a afirmar que "a representação visual seria, então, uma forma de controlar nossas emoções diante do visível” (Ibid., p. 28). A partir da estética é possível investigar como se constrói a realidade, uma realidade violenta, e como as imagens podem afetar, seja para retroalimentar uma dinâmica circular de violência ou para rompê-la. Se 
estética é uma questão de percepção, é também uma questão daquilo que se constrói como realidade, conforme apontam Merleau-Ponty e Watzlawick; daquilo que se comunica como violência - uma realidade violenta. A circularidade é a forma adotada pela violência na cidade; a circularidade da violência é a projeção de um padrão de interdependência que pode ser alterado pela perspectiva, segundo Watzlawick (WATZLAWICK, 1991, p. 44), dado que "não existe uma realidade absoluta mas apenas concepções da realidade subjetivas e muitas vezes contraditórias" (Ibid., p. 127).

A função essencial da percepção, segundo Merleau-Ponty, seria fundar ou inaugurar o conhecimento (MERLEAU-PONTY, 1999, p. 40), considerando a experiência perceptiva uma leitura dos mesmos dados sensíveis, mas de maneira mais rápida, a partir dos signos cada vez mais claros (Ibid., p. 210-211). O pensamento de perceber para Merleau-Ponty é fruto de uma experiência (Ibid., p. 67), que se constitui em um método calcado na experiência da vida e todos os mistérios que nela caibam, sem aprisionamentos, engessamentos ou apagamentos. A fenomenologia merleaupontyana é um método não restrito à percepção como uma operação intelectual, o que autoriza uma descrição direta da nossa experiência - vivida e diária, daquilo que nos afeta, das sensações, das imagens mentais e das lembranças. Este é o mundo sensível revelado através da percepção e projetado como realidade. Uma realidade observável através do método merleaupontyano, capaz de visibilizar o contexto deste mundo. A Fenomenologia da Percepção de Merleau-Ponty se configura em uma potência crítica; ademais, a crítica e a redução constituem meios para desvelar o mundo, acrescido seu caráter histórico e inclusa a compreensão do significado da experiência vivida, proporcionando a apreensão de todos os aspectos que envolvem a questão e, portanto, o entendimento do fenômeno de uma forma mais ampla (Ibid., p. 106-107). Neste sentido, o método fenomenológico de Merleau-Ponty sintoniza com a provocação de Debord sobre uma teoria crítica radical, construída para descobrir e não encobrir. É em Merleau-Ponty que as respostas surgem com a perspectiva do despertar da experiência perceptiva, considerando-se a percepção como iniciação ao mundo (Ibid., p. 346). Respostas que levam em conta a retirada da causalidade, de uma comunicação pelo seu sentido expresso no "olhar à distância" (Ibid., p. 349-350). Merleau-Ponty defende a renúncia da ideia de causalidade e de motivação, por acreditar que o "pretenso motivo não pesa em minha decisão, ao contrário, é minha decisão que lhe empresta sua força" (Ibid., p. 582), mas sem que isto signifique subtrair a possibilidade de "re-criação ou re-constituição do mundo" (Ibid., p. 279), ratificando a percepção como instalação do saber (Ibid., p. 280). O olhar de MerleauPonty é a essência sobre a potência de apreensão, sobre a construção de entendimento e sobre a ilusão referente à profundidade (Ibid., p. 353). Este é um método que coloca o observador do 
sujeito perceptivo como um sujeito perceptivo, destacando a percepção da maneira como é vivida pelo sujeito, o que acaba por desmentir seu pré-conceito sobre percepção, principalmente porque a perspectiva é interna e não externa (Ibid., p. 279).

O mundo exposto por Merleau-Ponty é aquele que já está ali. Segundo o filósofo, a reflexão não pode ser plena nem um esclarecimento total de seu objeto; ademais, é preciso saber procurar o sujeito que buscamos conhecer, sem nos tornarmos inteiramente consciência (MERLEAU-PONTY, 1999, p. 98). É a partir desta perspectiva que o real deve ser descrito, e não construído ou constituído, levando-se em consideração que nosso campo perceptivo é preenchido de reflexos, de projeções, reflexões e imaginações, "que não podem ser ligados de maneira precisa ao contexto percebido" (Ibid., p.5), explica Merleau-Ponty. O real não é uma realidade da minha percepção, nem esta é uma ciência do mundo, nem este é "um objeto do qual possuo comigo a lei de constituição" (Ibid., p.6), por esse motivo a opção por uma pesquisa que preconize a experiência como espaço aberto. A experiência fotográfica se apresenta como um meio para descrever este real. A partir desta forma de descrição é possível modificar a percepção sobre uma imagem comunicada como realidade e produzir outra realidade mediada pelo afeto. É a ampliação do meu campo de visão a partir do outro, de como o outro vê, pois é através da percepção de outrem que eu posso me encontrar posto em relação com um outro eu; uma percepção realizada a partir de outra subjetividade (MERLEAU-PONTY, 2015; p. 39). É a partir desta experiência perceptiva que se estabelece aquilo que Merleau-Ponty entende como "comunicação verdadeira", uma comunicação fundada nos elementos de uma descrição do mundo percebido (Ibid., p. 39), da síntese de um mundo fotografado.

Percepção é também o sentir, o afetar e se deixar afetar. $\mathrm{O}$ afeto carrega radicalmente a possibilidade para uma técnica que propõe ir além da observação. O afeto seria, então, a essência do ato perceptivo. Spinoza em seu livro "Ética" oferece inúmeras reflexões sobre afeto, inclusive sobre a possibilidade de ruptura do padrão circular, denominado pelo filósofo como "reciprocidade" (SPINOZA, 2017, p.126-128; 187; 203-204; 221). Para Spinoza a potência dos afetos se reflete por intermédio do nosso comportamento, que acaba projetado no outro. Esta projeção é a imagem que construímos a partir da nossa percepção sobre o outro. É nossa percepção que atribui um valor negativo ou positivo, somos nós que depositamos ou debitamos valor sobre as coisas, que consideramos se as coisas são más ou boas de acordo com nossa percepção. Spinoza defende a percepção como a faculdade de conceber e estaria relacionada ao corpo, convergindo com a concepção merleaupontyana sobre percepção: o corpo como centro da experiência perceptiva. É o canal perceptivo que nos permite afetar e sermos afetados, oferecendo a oportunidade de criar novas imagens e romper com outras imagens. O olhar 
estético do afeto amplia o campo perceptivo por intermédio do afeto, permitindo ver a partir de outras lentes e outros corpos. A câmera fotográfica seria um outro corpo capaz de produzir outra forma de ver, em transformar o ver em olhar, o olhar em agir. O que é o olhar senão um "apêndice do corpo", uma extensão da síntese corporal (MERLEAU-PONTY, 1999, p. 211212). O olhar, segundo Merleau-Ponty, “obtém mais ou menos das coisas segundo a maneira pela qual as interroga, pela qual ele desliza ou se apoia nelas" (Ibid., p. 212). Para o filósofo, a percepção "nasce no berço do sensível e não vem de outro lugar" (Ibid., p. 45), considerandoa o trânsito da significação. É no perímetro ampliado do campo visual que poderemos encontrar reflexos de superfícies sensíveis para podermos olhar ao invés de só vermos (DIDIHUBERMAN, 2015; 2010). Através da criação de novos campos visuais é possível fazer novas representações (MERLEAU-PONTY, 1999, p. 58). A Fotografia carrega uma alternativa de síntese perceptiva. Se os objetos reais não fazem parte do nosso campo visual, há que buscá-los em imagens, recomenda Merleau-Ponty, para que seja possível encontrar suas "possibilidades permanentes de sensações" (Ibid., p. 51). A fotografia pode ser o medium ideal deste instrumento para sensibilizar, criar um novo olhar e reterritorializar a cidade e suas relações.

\section{A experiência fotográfica como medium do olhar estético do afeto: o projeto Olhar Complexo}

Para Merleau-Ponty, a Fotografia se apresenta como um meio para descrever a experiência perceptiva, capaz de modificar a percepção sobre uma imagem comunicada como realidade e produzir outra realidade mediada pelo afeto. De acordo com a fenomenologia merleaupontyana, a percepção é minha porta para questionar e refletir sobre a estrutura daquilo que vejo, para que eu possa (re)construir o olhar. O mundo da concepção merleaupontyana não é aquilo que eu penso, mas aquilo que eu vivo; em outras palavras, é minha experiência que projeta aquilo que eu entendo de mundo. Esta é a experiência fotográfica proporcionada pela obra do Fotógrafo Bruno Itan e promovida em seu projeto Olhar Complexo, criado pelo próprio Bruno com o objetivo de formar um novo olhar dentro do Complexo do Alemão. Um olhar que seja capaz de modificar o próprio olhar dos moradores da favela, como também daqueles que moram no asfalto, acostumados a ver a favela e seus moradores como retratos da violência.

O projeto Olhar Complexo foi fundado em 2017, inspirado no "Foto Clube Alemão", projeto criado em 2011 por Bruno Itan, morador do Complexo do Alemão, e seu Mestre, Dhani Borges, como forma de "levantar a bandeira da fotografia no Complexo do Alemão, que sempre foi conhecido como o lugar aonde Tim Lopes morreu" ". Desde a sua fundação, o projeto ocupa uma sala no Centro de Referência da Juventude, localizado no Complexo do Alemão, 
coordenado por Lohran Santos, também morador desta favela. Um espaço que abriga diversos projetos organizados para e pela comunidade, voltados em sua maioria para a juventude, compreendendo atividades esportivas e profissionalizantes, além de cursos para adultos e idosos. O projeto estava em seu segundo ano quando foi feita a pesquisa, tendo formado 30 alunos no ano de 2017, entre crianças, adolescentes e adultos, e, em 2018, somente jovens e adultos participaram, registrando-se significativa redução da demanda infantil, atribuída, segundo Bruno, "à crescente violência que está dentro das comunidades", fazendo com que “as mães não deixem mais seus filhos andarem sozinhos pela favela”. Bruno ressalta que seu trabalho é voluntário, não contando com qualquer ajuda financeira, seja pública ou privada, ministrando quatro horas semanais, divididas em duas aulas, além das sessões de fotografia ao ar livre e eventos, o que permite aos alunos conhecerem outras favelas e sua própria comunidade, muitas vezes desconhecida para alguns deles, considerando-se que o Complexo do Alemão tem proporções municipais. Cabe salientar que o CRJ é subvencionado pelo governo do Estado do Rio de Janeiro, responsável por conceder a sala onde o curso é ministrado, aparelhado com mesas, cadeiras, projetor, computador e ar condicionado, todos em excelente estado de conservação. O equipamento fotográfico é do próprio Bruno Itan, e são raros os alunos que chegam com uma câmera que não seja a do celular, as exceções foram dois alunos adultos, uma moça e um rapaz que fotografavam antes de iniciarem o curso do projeto Olhar Complexo. Bruno salienta que não há exigência dos alunos possuírem uma câmera para participar do curso, justamente porque a intenção do projeto, como o próprio nome revela, é buscar esse olhar complexo: "a gente tá praticando é o olhar", dando origem ao nome, explica Itan, "a câmera vem depois". Ainda que seja evidente a falta de recursos, surpreende como Itan consegue manter a qualidade do projeto, replicando o curso que o apresentou ao mundo da Fotografia. Itan deposita na própria experiência afetiva a explicação para manter um projeto centrado em um objeto muitas vezes inacessível para a maioria dos moradores da favela e considerado elitista: "são oportunidades que eu acho que lá no final isso vai ser revertido pra mim com coisa boa, fazendo coisa boa, gerando coisa boa, sempre retorna pra você coisa boa, né? É assim que funciona a vida, assim que eu acho que funciona". Bruno destaca que o curso não é profissionalizante, ainda que admita seja uma "entrada no meio da fotografia, porque você sabe que trabalhar com fotografia é tudo caro, nenhum pessoal pode, você sabe que as pessoas que moram nas comunidades, nas favelas não tem essa tanta condição de comprar um equipamento bom, um equipamento profissional, então primeiro a gente tem que mostrar o sentimento, através do sentimento que a gente criar é que eles vão correr atrás dos equipamentos, mesmo com a dificuldade, como eu também tive a dificuldade." 
Além de representar uma porta de entrada para o mercado de trabalho, o projeto Olhar Complexo é um veículo para construção da memória social, reconhecido pelo próprio Itan ao discorrer sobre seu projeto, ilustrando a importância do processo de produção de memória do Complexo do Alemão: "é importante a gente mostrar o lugar aonde a gente vive, porque daqui a vinte, trinta anos, as pessoas vão querer saber como eram essas favelas, como que era esses lugares. Então, olha como é bom, é importante ter este registro e mostrar futuramente como era este lugar e como pode ser mostrar, essas pessoas daqui a vinte anos, vão sentir esse mesmo sentimento, vão querer registrar e daqui a cinquenta anos elas vão fazer isso e é isso que a gente tenta passar esse sentimento um pro outro." O projeto permite aos alunos descobrirem suas raízes, o espaço onde vivem e constroem seus laços, promovendo a autoestima e a construção de uma resistência a partir da sensibilização em relação ao próprio território e suas relações, visibilizados pelo ver fotográfico. É a partir daquilo que veem e projetam que a consciência da luta pelo direito à cidade é despertada, conforme preceituava Henri Lefebrve. Alguns alunos instintivamente percebem no projeto um meio de construção de memória, além da oportunidade da formação profissional e da inserção no mercado de trabalho, de acordo com a fala recorrente da maioria dos jovens matriculados no curso de Fotografia. São vários os relatos sobre a ausência de registros de infância, quando os celulares com câmeras fotográficas ainda não tinham sido popularizados, e a repercussão desta falta de memória fotográfica de suas histórias e da história do espaço onde cresceram, principalmente por considerarem importante possuírem imagens que os permitiriam comparar ou lembrar uma época das suas vidas. Essas imagens permitiriam acompanhar a evolução do próprio corpo, do seu território e da sua história. Essa ausência de registro do espaço onde moram, segundo o relato emocionado de uma aluna adolescente, seria responsável por interferir no ambiente, o que remete à potência da experiência estética, aquela capaz de reunir afeto e percepção e alterar o entorno. Itan defende o registro do cotidiano como forma de construir a memória do espaço onde vive, onde costurou seus laços de afeto, ou seja, suas imagens do Complexo do Alemão, os registros dos afetos da favela, vista pelo fotógrafo como um território de belezas, revelando o objetivo do Olhar Complexo, qual seja, desconstruir a imagem unilateral da favela, retratada como espaço de violência. Bruno Itan entende as saídas fotográficas durante o curso que ministra como uma experiência cultural e como registro de memória, pensando, inclusive, como material de exposição, não como exposição da violência. As imagens produzidas na favela se constituem como objeto cultural do cotidiano da favela. São imagens que não refletem aquelas retratadas pelo asfalto.

O olhar complexo de Bruno Itan é um olhar de ruptura com a identificação da favela 
como território de risco, o que ratifica a necessidade de expor as imagens feitas pelos moradores da favela para que se possa construir outra imagem da cidade. Bruno acredita que a fotografia contribui para alterar o ciclo de violência urbana, pois "a fotografia ajuda ao povo a lutar com a imagem, mais do que lutar com a arma; acho que isto já diz tudo”. Ele dispara: "Um tiro você pode matar uma pessoa, com uma imagem você pode acabar com um monte de gente", enfatizando o poder destruidor que uma imagem pode ter e sobre a imagem como denúncia. É sobre esse distanciamento que os espaços são identificados em imagens sem palavras. Bruno busca sempre destacar que seu objetivo com o projeto Olhar Complexo é mudar o olhar sobre a favela, reprogramando o olhar negativo em positivo. Todavia, Bruno parece querer demonstrar não perceber a própria potência do seu trabalho para romper a circularidade da violência, ou, então, deseja afastar a responsabilidade do que para ele seria "resolver $o$ problema da violência"; declarando não intencionar nenhuma "mudança na questão da violência, "não vem de mim mudar essa questão, vem do meu trabalho ajudar", "e sim, mostrar uma perspectiva de vida diferente pras pessoas; oportunidades diferentes de emprego, de arte, de uma cultura diferente [...] Eu acho que eu consigo mudar a imagem de um lugar com a fotografia, mostrar uma perspectiva de vida, de oportunidades diferentes que você pode ter de emprego, financeiramente ou culturalmente, é, pra essas pessoas. Mas acho que violência, acho que a fotografia ela não, não a que eu tô fazendo, porque eu poderia usar aqui todas as fotos que eu faço, eu faço fotojornalismo."

O projeto Olhar Complexo ratifica a possibilidade de reterritorialização através do afeto, expressa na narrativa dos alunos, que depositam no curso uma oportunidade para gerar outra imagem sobre a realidade da comunidade, onde "a gente leva outra imagem pras crianças. A gente já conheceu muitas crianças que a vontade era ser traficante e a gente trabalhando com elas, a gente conversando no dia-a-dia foi mudando a realidade e fomos mostrando uma outra perspectiva de vida. Então através da fotografia isso pode ser mudado também.", relata um aluno. Para outro aluno, "a fotografia consegue travar a violência”; "a fotografia, depois que você clica, ninguém mais pode mexer, ninguém pode mudar aquela realidade. Então, quando o fotógrafo tá, tá numa, tá cobrindo uma operação policial, o policial talvez não pense em querer agir de alguma maneira mais absurda porque ele sabe que vai tá registrado, entendeu? Então eu acho que a fotografia vai inibir um pouco a, a visão assim, da forma que o policial age numa comunidade. Por isso trava, trava." Fica evidente na fala de alguns alunos que a visibilidade desses projetos e da própria fotografia é fator decisivo para promover a alteração da modulagem de percepção social e a consequente ruptura do padrão circular de violência que divide a cidade e marca suas relações. Uma forma de reconstruir a memória da favela e projetar 
outra imagem, abrindo caminho para outras possibilidades de presente e futuro.

A própria história de Bruno Itan revela uma dessas memórias do Complexo do Alemão. Uma história que é quase um clichê, igual a de tantas outras crianças que migraram com seus pais do nordeste para o Rio de Janeiro buscando melhores condições de vida; a história de inúmeras mães que assumem sozinhas a criação de seus filhos. Embora Itan reconheça o impacto da violência em sua história, os laços de afeto costurados durante a infância mostraram o outro lado da favela e redesenharam sua história, fazendo com que "crescesse gostando mesmo do Rio de Janeiro; eu me apaixonei pela favela." Um dos seus relatos mais marcantes é sobre o despertar deste afeto, quando a professora do colégio pediu para que os alunos pesquisassem imagens dos locais de suas moradias na internet ou fizessem colagem de jornais e revistas, mostrando "o lado bom” onde eles viviam. Em sua pesquisa, Bruno só encontrara imagens que retratavam o Complexo do Alemão como um espaço de violência: "as imagens eram só de tiroteio, gente morta e violência, que no Complexo do Alemão só tem bandido”. Aquelas imagens não refletiam a realidade do cotidiano de Bruno. Onde estavam "o sol, as crianças jogando bola, soltando pipa, o sorriso dos moradores, churrasquinho na laje no final de semana, o campeonato de futebol, torneio de pipa, as crianças brincando de bola de gude, de pião", que Bruno via no Complexo do Alemão? Foi aí que Bruno viu "que não se compra isso, que isso não é interessante pra ninguém”, referindo-se às imagens que tinham despertado sua paixão pelo Rio de Janeiro e pelo Complexo do Alemão e que não faziam parte das imagens divulgadas "pela grande mídia, jornais, revistas". Nenhuma daquelas imagens que Bruno encontrara refletiam "o lado bom do Complexo do Alemão”, levando-o a concluir que só produziam imagens negativas sobre a favela, "fazendo com que ninguém conheça o lado bom, só conheçam o lado ruim, porque ninguém nunca mostra o lado bom”. Foi neste momento que Bruno percebeu que a favela era vista como o lado feio da cidade, justamente porque só viam uma imagem da favela, aquela veiculada pelos meios de comunicação e que nunca mostravam o lado bonito daquele espaço. Uma imagem negativa que se reflete na favela e acaba por modular a percepção dos próprios moradores. Foi naquele momento que Bruno percebeu qual era o seu objetivo na vida: "um dia poder mostrar as flores que tem lá na minha rua e porque eu acho minha rua bonita, meu beco, a fiação, a arquitetura da favela, que pra mim, eu achava bonito, mas na minha opinião eu também achava que o pessoal lá fora também não achava bonito porque era feio e eu não entendia”. Bruno despertara para a diferença e o desejo de comunicar aquilo que ele via e que muitos não viam na favela. Bruno queria que olhassem para favela por intermédio de outras lentes - suas lentes, as lentes de afeto. Como Bruno não conseguira encontrar imagens que retratassem sua realidade, desenhou as belezas que via, 
explicando à professora os motivos que o levara a tal decisão. A professora, desconcertada, foi obrigada a admitir que Bruno, o único aluno não residente na região próxima ao colégio, não tinha outra opção não fosse desenhar "o lado bom do Complexo do Alemão”, "aí eu desenhei flores, eu desenhei futebol, desenhei bola, eu desenhei coisas que na minha cabeça eu achava bonito"; "aí ela me deu dez". Foi assim que Bruno tivera a certeza da necessidade em mostrar o lado bonito da favela, aquela imagem "que ninguém conhece". Tal como Barthes (BARTHES, 2015, p. 26), a relação de Bruno com a fotografia é baseada no sentimento; já a relação do espectador com a fotografia, entre studium e punctum, entre deixar-se ou não afetar (Ibid., p. 27).

Este relato de Bruno revela a violência simbólica que os moradores das favelas são vítimas, principalmente as crianças. É uma associação entre favela e violência que estigmatiza a vida, por uma vida inteira. O sujeito inicia sua vida sendo identificado - e se identificando com a imagem da violência, como indivíduo violento, morador de um espaço violento e que só é capaz de gerar mais violência. As alternativas de descolar da imagem construída unilateralmente são mínimas, restringidas pela comunicação violenta. É este retrato que Bruno se recusou identificar e a ser identificado. O Olhar Complexo de Bruno Itan busca estimular a dissociação da imagem da favela retratada como locus de violência e desconstruir a representação da favela como emblema da violência. Itan vê no ato de fotografar uma possibilidade de romper com o medo gerado em razão desta construção imagética que impõe repressão e controle à favela. $\mathrm{O}$ ato de fotografar carrega a possibilidade de afetar, fazer afetar e promover identificações. Fotografar é o seu "agir sobre", é a oportunidade de buscar transformar através do afeto. $\mathrm{O}$ medo experimentado pelos moradores do Complexo do Alemão se refletem nas manifestações pelo desejo da pacificação, conforme exposto pela maioria dos alunos do projeto Olhar Complexo. Uma aluna acredita que o afeto seja responsável por trazer essa paz: "eu acho assim, quando a gente tem este afeto, cria este afeto com as pessoas, [...] com o afeto a gente chegar mais longe, consegue fazer outras coisas, é isso gera paz". Muitos alunos do projeto acreditam que fotografar é transmitir afeto, uma forma de "passar a visão", pois a fotografia seria capaz de traduzir suas emoções em imagens, tendo o idealizador do projeto como paradigma para mudar suas imagens e a imagem da favela. Estas emoções se refletem nas imagens dos alunos, intensas e genuínas, puro punctum, demonstradas nas palavras que expressam o desejo de afetar e transformar através da imagem fotográfica. Um afeto transformador que eles encontram nas fotos de Itan: "Ele, através de uma imagem, ele conta uma história de quando aquela pessoa tinha bem antes até ela chegar ali, como ela chegou ali. Eu já foco meu tempo de imagem, já é aquele momento. Quando você olhar vai enxergar aquele 
momento, aquela vivência, aquela experiência daquele momento, daquele instante, porque aquela imagem saiu assim." O olhar complexo de Bruno demonstra as camadas possíveis do tempo, os caminhos de chegada e partida das imagens, como elas podem afetar através do tempo, abrindo e fechando o próprio tempo, como Rancière aponta em seu livro "O Destino das Imagens" (RANCIÈRE, 2012). Esta potência do olhar restou verbalizada por uma aluna: "é o meu olhar, porque eu capto ali as emoções das pessoas, do momento que tá se passando e aí depois eu vou pensar nas outras pessoas que vão olhar as fotos. Eu não consigo captar as imagens pensando no que o outro vai ver. Até porque as pessoas cobram muito isso. O fazer foto pra mim e não pras outras pessoas. Mas eu capto de imediato o que eu tô enxergando, aquilo que eu tô vendo, as emoções que eu tô sentindo e aí eu vou e foco naquilo." Pergunto à aluna se acredita que seu sentimento é capaz de ser transmitido através das suas fotos, e se através dessa foto ela consegue atingir com o mesmo sentimento quem olha suas fotos; ela hesita em me responder: "às vezes sim, a maioria das vezes sim, porque as pessoas veem emoção nas minhas fotos".

O trabalho de Bruno Itan é este outro olhar, aquele que pretende revelar "aquela gente bonita, solidária, inteligente, aqueles lugares lindos", a projeção daquilo que o fotógrafo vê no Complexo do Alemão e "que nunca serão revelados se a iniciativa não partir daqueles que aqui vivem. Acho que o nosso papel é mostrar as favelas vão além do que é divulgado cotidianamente”. O fotógrafo Bruno Itan admite a possibilidade de mudança de percepção através da fotografia ao "passar afeto", capaz de alterar a percepção de "quem vê a fotografia e de quem fotografa". Bruno declara que percebe mudanças na percepção dos alunos em relação ao espaço onde vivem e na autopercepção. Esta é a experiência que o projeto de Bruno Itan proporciona. Uma experiência que representa a amplitude da mediação oferecida pelo olhar estético do afeto. A experiência do olhar complexo de Bruno Itan é a experiência preconizada por Walter Benjamin de uma imagem dialética, voltada para aquilo que entendemos como tempo futuro, mas calcada numa construção do tempo passado. É esta possibilidade de diálogo entre uma imagem já formulada e uma imagem complexa, proposta por Català Domènech. Um olhar sobre uma imagem capaz de afetar, provocar reflexões críticas e alterar percepções do vivido na possibilidade do porvir. Este também é o olhar estético do afeto, como possibilidade de construção de uma memória percebida e aquela que se estrutura na abertura do tempo.

A Fotografia é uma interminável multiplicidade de imagens que portam a potência de (se) transformar (AZOULAY, 2008, p. 145), uma espécie de guia, tal como é o meu próprio olhar, na medida que me permite diferenciar do outro/de outra paisagem, como também me identificar com este outro/esta outra paisagem (MERLEAU-PONTY, 1999, p. 543). O punctum 
na imagem seria aquilo que me toca, me afeta, me punge, desperta o meu olhar (BARTHES, 2015, p. 25), e pode me transformar porque provoca meu agir. $\mathrm{O}$ ato de fotografar é o mergulho na imagem da Fotografia através do meu olhar a partir do olhar do outro, para, assim, voltarme para mim - que percebo, como preconiza Merleau-Ponty. Ao fotografar eu me projeto no mundo e, ao mesmo tempo, eu mostro como eu vejo o mundo, eu construo um novo mundo, uma nova realidade. A experiência fotográfica é uma oportunidade que todos ganham em ver através do olhar do outro (AZOULAY, 2008, p. 107). O olhar estético do afeto expõe essa prerrogativa da imagem, do despertar da experiência perceptiva através do olhar do outro. As imagens produzidas no curso de Fotografia do projeto Olhar Complexo reconfiguram a visibilidade social daquilo que é determinado socialmente para ser visto, projetado como imagem da violência, do imaginado como obstáculo para se alcançar aquilo que Itan e muitos moradores do Complexo do Alemão consideram a paz. A realidade daqueles Fotógrafos está

projetada nessas imagens. É a partir do ponto de vista de Bruno e seus alunos que podemos olhar aquele espaço e estabelecer outro padrão comunicativo. Seria a reprogramação dos afetos por intermédio da imagem proposta por Spinoza (SPINOZA, 2017, p. 216). É certo que todas as imagens têm a capacidade de despertar algum tipo de emoção no espectador (CATALÀ DOMENĖCH, 2011, p. 28) e o curso de Fotografia carrega a possibilidade de múltiplos despertares em todos os espaços, por isso emerge como medium de uma técnica para modular e calibrar a percepção; afinal, fotografar é poder mediar as relações sociais e políticas entre os cidadãos, como também as relações entre os cidadãos e o poder (AZOULAY, 2008, p. 137138).

\section{Conclusão}

Buscamos com este trabalho apresentar não só uma alternativa às políticas públicas que pretendem enfrentar a violência com mais violência, mas a oportunidade de reterritorialização da cidade e suas relações através da experiência fotográfica. A Fotografia oferece uma forma de experiência estética capaz de reunir a experiência afetiva e a experiência perceptiva. Esta experiência exprime a essência do olhar estético do afeto, uma técnica que busca ampliar a percepção e promover a emancipação do ver para construir outros olhares, outras imagens. $\mathrm{O}$ projeto Olhar Complexo, criado e dirigido pelo Fotógrafo Bruno Itan, é um exemplo como o olhar estético do afeto atua e permite modificar o olhar e romper com um determinado padrão perceptivo. O olhar despertado por intermédio do projeto porta radicalmente a possibilidade de ir além da observação, expressa na raiz da palavra afeto, afficere, que significa fazer algo, agir 
sobre algo. A experiência fotográfica pode reprogramar o olhar a partir de imagens que despertem outros afetos. A reestruturação perceptiva permite processar a desestigmatização, tanto do sujeito quanto do espaço. É a possibilidade de reconfiguração do padrão comunicativo a partir da ativação do sensível. O projeto Olhar Complexo expõe a potência de um curso de Fotografia gerado dentro das favelas para moradores da favela, oferecendo a chance de afetar as relações em uma cidade desigual e comunicada como violenta em razão de um olhar unilateral e desafetado. Uma experiência que pode auxiliar no processo de alteração de percepção do morador do asfalto em relação à favela, como também do próprio morador da favela em relação ao espaço onde vive e a autopercepção, além da possibilidade de construção de memória social. Esta é a oportunidade de reterritorializar a cidade e suas relações. 


\footnotetext{
${ }^{1}$ Todas as entrevistas realizadas durante a pesquisa de doutorado foram gravadas e encontram-se arquivadas com a autora. As transcrições de trechos de entrevistas foram dispostas neste artigo sem edição, entre aspas e em itálico, segundo as normas da ABNT para transcrição de entrevistas.
}

\section{Referências}

ARENDT, Hannah. A Condição Humana. 10. ed. Rio de Janeiro: Forense Universitária, 2007. AZOULAY, Ariella. The Civil Contract of Photography. New York: Zone Books, 2008.

BARTHES, Roland. A câmara clara: nota sobre a fotografia. Rio de Janeiro: Nova Fronteira, 2015.

BENJAMIN, Walter. Escritos sobre mito e linguagem (1915-1921). 2. ed. São Paulo: Editora 34, Coeditado pela Livraria Duas Cidades, 2013.

BENJAMIN, Walter. Estética e sociologia da arte. Belo Horizonte: Autêntica Editora, 2017.

BERLEANT, Arnold. The Aesthetic Field: a phenomenology of aesthetic experience.

Cybereditions, 2000.

CATALÀ DOMÈNECH, Josep M. La Imagen Compleja: la fenomenologia de las imágenes em la era de la cultura visual. Balleterra (Barcelona): Universitat Autònoma de Barcelona, 2005.

CATALÀ DOMÈNECH, Josep M. A forma do real. São Paulo: Summus, 2011.

CORTINA, Adela. Aporofobia, el rechazo al pobre. Barcelona: Espasa Libros, 2017. Edição eletrônica.

DIDI-HUBERMAN, Georges. O que vemos, o que nos olha. 2. ed. São Paulo: Editora 34, 2010.

DIDI-HUBERMAN, Georges. Diante da Imagem. São Paulo: Editora 34, 2015.

GUSTIN, Miracy Barbosa de Sousa et.al. (Re)pensando a pesquisa jurídica: teoria e prática. 3. ed. Belo Horizonte: Editora Del Rey, 2010.

KOSSOY, Boris. Realidades e ficções na trama fotográfica. 5. ed. São Paulo: Ateliê Editorial, 2016.

LUHMANN, Niklas; DE GIORGI, Raffaele. Teoria de la Società. 11. ed. Milano: FrancoAngeli, 2003.

MARTINS, José de Souza. Sociologia da fotografia e da imagem. 2. ed. São Paulo: Contexto, 2017.

MERLEAU-PONTY, Maurice. Fenomenologia da Percepção. São Paulo: Martins Fontes, 1999. 
MERLEAU-PONTY, Maurice. O primado da percepção e suas consequências filosóficas. Belo Horizonte: Autêntica Editora, 2015.

ROCHA, Ailton Schrmamm et. al.. Metodologia de pesquisa em Direito e a filosofia. São Paulo: Saraiva, 2011.

SONTAG, Susan. Sobre Fotografia. São Paulo: Companhia das Letras, 2004. Versão eletrônica.

SPINOZA, Benedictus de. Ética. 2. ed. Belo Horizonte: Autêntica Editora, 2017.

WATZLAWICK, Paul. A Realidade é Real? Lisboa: Relógio d’Água Editores, 1991. 